\title{
In vitro Study of Reactive Oxygen Species Production during Photodynamic Therapy in Ultrasound-Pretreated Cancer Cells
}

\author{
H. KOLÁŘOVÁ, R. BAJGAR, K. TOMÁNKOVÁ, E. KRESTÝN, L. DOLEŽAL, J. \\ HÁLEK
}

Department of Medical Biophysics, Faculty of Medicine, Palacký University, Olomouc, Czech

Republic

Received May 23, 2007

Accepted May 29, 2007

On-line available May 31, 2007

\begin{abstract}
Summary
Several recent studies bring evidence of cell death enhancement in photodynamic compound loaded cells by ultrasonic treatment. There are a number of hypotheses suggesting the mechanism of the harmful ultrasonic effect. One of them considers a process in the activation of photosensitizers by ultrasonic energy. Because the basis of the photodynamic damaging effect on cells consists in the production of reactive oxygen species (ROS), we focused our study on whether the ultrasound can increase ROS production within cancer cells. Particularly, we studied ROS formation in ultrasound pretreated breast adenocarcinoma cells during photodynamic therapy in the presence of chloroaluminum phthalocyanine disulfonate $\left(\mathrm{ClAlPcS}_{2}\right)$. Production of ROS was investigated by the molecular probe $\mathrm{CM}-\mathrm{H}_{2} \mathrm{DCFDA}$. Our results show that $\mathrm{ClAlPcS}_{2}$ induces higher ROS production in the ultrasound pretreated cell lines at a concentration of $100 \mu \mathrm{M}$ and light intensity of $2 \mathrm{~mW} / \mathrm{cm}^{2}$. We also observed a dependence of ROS production on photosensitizer concentration and light dose. These results demonstrate that the photodynamic effect on breast cancer cells can be enhanced by ultrasound pretreatment.
\end{abstract}

Key words

Photodynamic therapy $\bullet$ Sonodynamic therapy $\bullet$ Phthalocyanine sensitizer $\bullet$ Reactive oxygen species

\section{Introduction}

Sonodynamic therapy (SDT) is based on selective accumulation of sonosensitizing drugs in pathological tissues and subsequent activation of the sonosensitizers by ultrasound. SDT is used to induce cavitation, redistribution and disaggregation of the drugs, which in monomer forms produce a higher cytotoxic effect. In addition, the method has an advantage when compared to other physical treatment modalities in selective action because of the ability to focus ultrasonic energy into a small volume. Up to this day, several different chemical substances have been reported as potent sonosensitizers including porphyrins (Yumita et al. 1989, Umemura et al. 1990,), pheophorbide a (Umemura et al. 1990), dimethylformamide (Jeffers et al. 1995), merocyanine (Tachibana et al. 1999), piroxicam (Sakusabe et al. 1999), tenoxicam (Sakusabe et al. 1999), 
erythrosine B (Umemura et al. 1997, Hiraoka et al. 2006), rhodamine derivatives (Hiraoka et al. 2006), and phthalocyanines (Milowska and Gabryelak 2005). Considering that there are also a number of hypotheses trying to explain the principle of ultrasound action, it seems that the process includes several different physicochemical mechanisms. Umemura et al. (1996) suggest that a synergistic effect of ultrasound and sonosensitizers is due to photoexcitation of the drug by the sonoluminescence produced in collapsing cavitation. The mechanism of sonosensitization can also involve facilitated accumulation, redistribution and monomerization of the sonosensitizers (Misik and Riesz 1996, Miyoshi et al. 2001, Larina et al. 2005). Kessel et al. (1994) suppose that cytotoxicity is mediated largely by inertial cavitation. Inertial cavitation is a process where a gas bubble created by ultrasound in a liquid rapidly collapses, producing a shock wave with intense heat release (several thousand degrees Kelvin) (Worthington et al. 1997). The water molecules surrounding the cavitation decompose into their $\mathrm{H}$ and $\mathrm{OH}$ constituents (water pyrolysis), which either recombine, form $\mathrm{H}_{2} \mathrm{O}, \mathrm{H}_{2} \mathrm{O}_{2}$ and $\mathrm{H}_{2}$, directly oxidize or reduce solute molecules, sonosensitizers or the biomolecules (Suslick 1990). Free radical formation due to ultrasound action is strongly dependent on its threshold acoustic pressure at specific frequencies (Riesz and Kondo 1992).

Phthalocyanines belong to a second generation photosensitizers and are reported as being among the most effective drugs for photodynamic therapy (PDT) (Zavodnik et al. 2002). PDT is a promising therapy of malignant and nonmalignant diseases where the combined effect of photosensitizer, visible light and oxygen induces cell death. Upon absorption of appropriate light wavelengths, the photosensitizer is excited into a highenergy state, from which it is returned, accompanied by the transfer of an electron to adjacent molecules, referred to as a type I photochemical reaction, or energy to ground state of molecular oxygen, type II photochemical reaction (Henderson and Dougherty 1992, Nyman and Hynninen 2004). These processes produce reactive oxygen species (ROS) that are harmful to cells, such as singlet oxygen ${ }^{1} \mathrm{O}_{2}$, superoxide radical anion $\mathrm{O}_{2}{ }^{-}$, hydroxyl radical ${ }^{\circ} \mathrm{OH}$, and hydrogen peroxide $\mathrm{H}_{2} \mathrm{O}_{2}$.

The aim of this study was to examine the effect of ultrasound exposure on ROS formation during subsequent PDT of breast adenocarcinoma cell line MCF7 in the presence of chloroaluminum phthalocyanine disulfonate $\mathrm{ClAlPcS}_{2}$.

\section{Methods}

\section{Cell culture and sensitizers}

The MCF7 (human breast adenocarcinoma cell line) (ATTC, USA) was grown in $35 \mathrm{~mm}$ cell culture dishes $\left(3.3 \times 10^{5}\right.$ cells $)$ in the presence of cultivation medium DMEM. Cell culture was stored in a humidified $\mathrm{CO}_{2}$ incubator $\left(37^{\circ} \mathrm{C}, 5 \% \mathrm{CO}_{2}\right)$ for $24 \mathrm{~h}$. The cells in DMEM were then loaded with $0,1,10$ and $100 \mu \mathrm{M}$ phthalocyanine sensitizer $\mathrm{ClAlPcS}_{2}$ prepared by Jan Rakusan at the Research Institute for Organic Syntheses in Rybitvi (Czech Republic) and incubated for subsequent $24 \mathrm{~h}$.

\section{Microscopy}

Intracellular ROS production was detected using the nonfluorescent compound CM- $\mathrm{H}_{2}$ DCFDA (Invitrogen Corporation, USA). Upon crossing the membrane, the compound undergoes deacetylation by intracellular esterases producing the nonfluorescent $\mathrm{CM}-\mathrm{H}_{2} \mathrm{DCF}$, which quantitatively reacts with oxygen species inside the cell to produce the highly fluorescent dye CM-DCF. This compound remains trapped within the cell. Cells loaded with $100 \mu \mathrm{M} \mathrm{ClAlPcS} S_{2}$ were treated with $5 \mu \mathrm{M} \mathrm{CM}$ $\mathrm{H}_{2}$ DCFDA for 30 min in darkness and then irradiated by light emitting diodes (LEDs; 635 nm, FWHM 20 nm, 1 $\mathrm{mW} / \mathrm{cm}^{2}$ ) for $10 \mathrm{~min}$. Production of ROS was visualized by inverted fluorescence microscope Olympus IX 70 equipped with Olympus DP70 digital camera.

\section{Ultrasound treatment}

Ultrasound generator BTL-4000 (BTL, USA) with a transducer area of $4 \mathrm{~cm}^{2}$, frequency $1 \mathrm{MHz}$ and intensity $2 \mathrm{~W} / \mathrm{cm}^{2}$ was used for induction of the sonodynamic effect. The ultrasonic intensity output from the transducer was calibrated by radiation force balance against a primary standard and high performance hydrophone measurement system. After 24-h cell incubation with sensitizer, DMEM was replaced with PBS containing $5 \mathrm{mM}$ glucose and $10 \mu \mathrm{M}$ CM$\mathrm{H}_{2}$ DCFDA, and stored in a thermobox for $20 \mathrm{~min}$ at 37 ${ }^{\circ} \mathrm{C}$. Then the extracellular probe was washed out by fresh glucose-enriched PBS and cells on $35 \mathrm{~mm}$ culture dishes were sonicated for $10 \mathrm{~min}$ at continuous rotation of 15 rpm and temperature of $37^{\circ} \mathrm{C}$.

\section{ROS measurement}

The assay using $\mathrm{CM}-\mathrm{H}_{2}$ DCFDA is especially sensitive to the increased production of hydrogen 

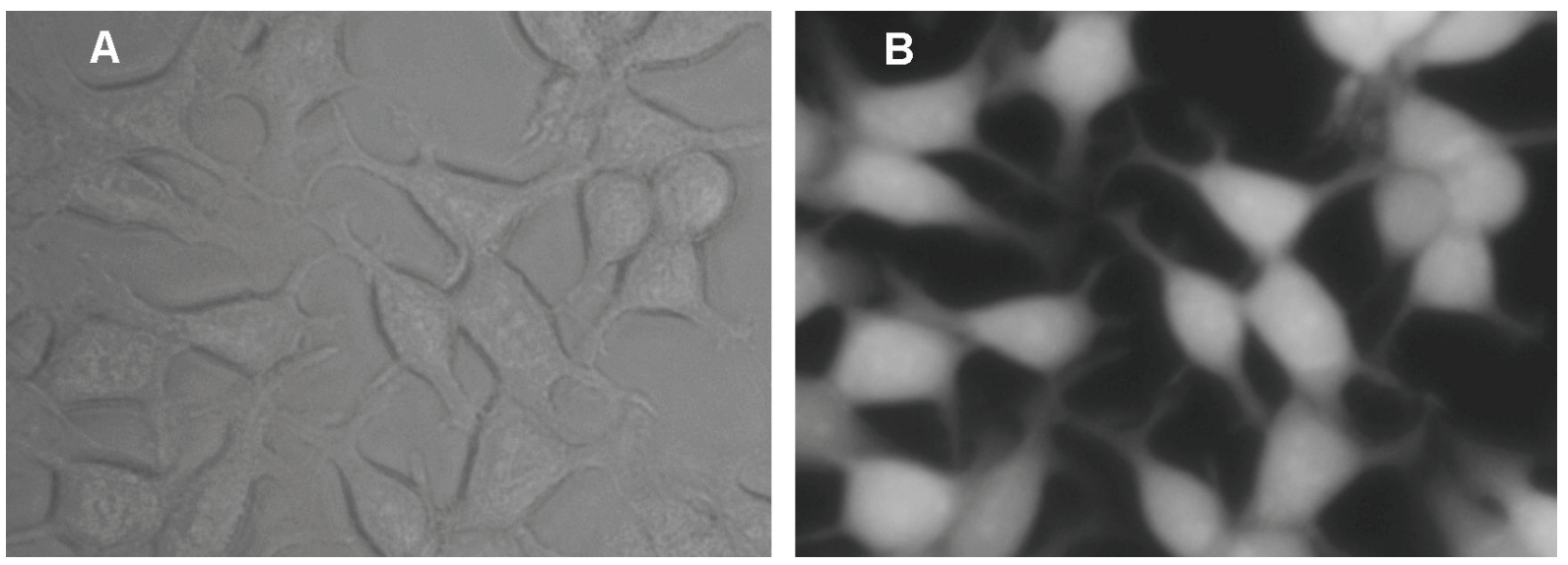

Fig. 1. Microscopic images of live MCF7 cells loaded with $100 \mu \mathrm{M} \mathrm{CIAIPCS}_{2}$ in transmitted light (A, original image at 400x magnification). Fluorescence image of cells treated with $5 \mu \mathrm{M} \mathrm{CM}-\mathrm{H}_{2}$ DCFDA followed by 10 min irradiation shows the localization of its oxidation (B; fluorescence image at excitation of CM-DCF, original image at $400 \times$ magnification).

peroxide or some of its downstream products (LeBel et al. 1992). Fluorescence of CM-DCF within cells adhered on a 35 -mm culture cell dish (excitation and emission filter were $485 / 20 \mathrm{~nm}$ and $540 / 25 \mathrm{~nm}$, respectively) was recorded as a kinetic measurement by Synergy HT reader equipped with a 5-mm reading probe from 4 places (BioTek, USA). The cells were continuously and homogeneously irradiated by 12 LEDs at a light intensity of $5 \times 10^{-4} \mathrm{~W} / \mathrm{cm}^{2}, 1 \times 10^{-3} \mathrm{~W} / \mathrm{cm}^{2}$ and $2 \times 10^{-3} \mathrm{~W} / \mathrm{cm}^{2}$. Other cells were exposed to a light irradiator consisting of 85 LEDs at a spatial homogeneous intensity of $20 \times 10^{-3}$ $\mathrm{W} / \mathrm{cm}^{2}$ for $8 \mathrm{~min}$ and $20 \mathrm{~s}$. Irradiance was measured by the radiometer system IL 1705 (International Light Technologies, USA). Fluorescence of CM-DCF was calibrated according to the corresponding fluorescence response of the probe to the additions of external $\mathrm{H}_{2} \mathrm{O}_{2}$. Briefly, cultured control cells in the absence of sensitizer were incubated with CM- $\mathrm{H}_{2}$ DCFDA. After removal of the extracellular probe by $2 \mathrm{~mL}$ of fresh PBS media, we recorded the increases of fluorescence signal in dependence on additions of 10,25 , and $50 \mu 1$ of $20 \mathrm{mM}$ $\mathrm{H}_{2} \mathrm{O}_{2}$, followed with $50 \mu \mathrm{L}$ of $200 \mathrm{mM} \mathrm{H}_{2} \mathrm{O}_{2}$.

\section{Data analysis}

The data illustrate either representative traces or means \pm standard errors for 3 independent experiments. One-way analysis and Student's t-test were used for comparisons between experimental groups. Significance was set at $\mathrm{p}<0.05$.

\section{Results}

\section{Microscopy}

The morphology of the adherent human breast carcinoma cells MCF7 is shown in transmitted light in Fig. 1.A. Molecular probe $\mathrm{CM}-\mathrm{H}_{2}$ DCFDA in photosensitized cells visualized the ROS production sites after $10 \mathrm{~min}$ of irradiation. After this period we could observe CM-DCF fluorescence diffusely localized within the whole cell (Fig. 1B). The microscopic technique used is not able to recognize whether there are any subcellular structures that are excluded from the ROS production because of the high depth of focus.

\section{ROS measurement}

The effect of sensitizer $\mathrm{ClAlPcS}_{2}$ concentration on ROS formation in ultrasound pretreated MCF7 cells was continuously monitored during application of PDT (Fig. 2). For the individual time course curve we calculated a rate of ROS production for the first four min using a linear regression analysis. The summary of the rate values for various sensitizer concentrations, light intensities and the effect of ultrasound pretreatment is presented in Fig. 3. Another experiment reported in Fig. 4 studied the total ROS production after the application of a $10 \mathrm{~J} / \mathrm{cm}^{2}$ light dose. The data showed that there is a significant difference of ROS production when we compared all the used sensitizer concentrations while a significant effect of sonication was expressed only for the application of a light intensity of $2 \times 10^{-3} \mathrm{~W} / \mathrm{cm}^{2}$ or a total dose of $10 \mathrm{~J} / \mathrm{cm}^{2}$ in incubated cells with $100 \mu \mathrm{M}$ $\mathrm{ClAlPcS}_{2}$.

\section{Discussion}

In the present study we examined whether the application of an ultrasound treatment can induce an increase of ROS within breast adenocarcinoma cell line 


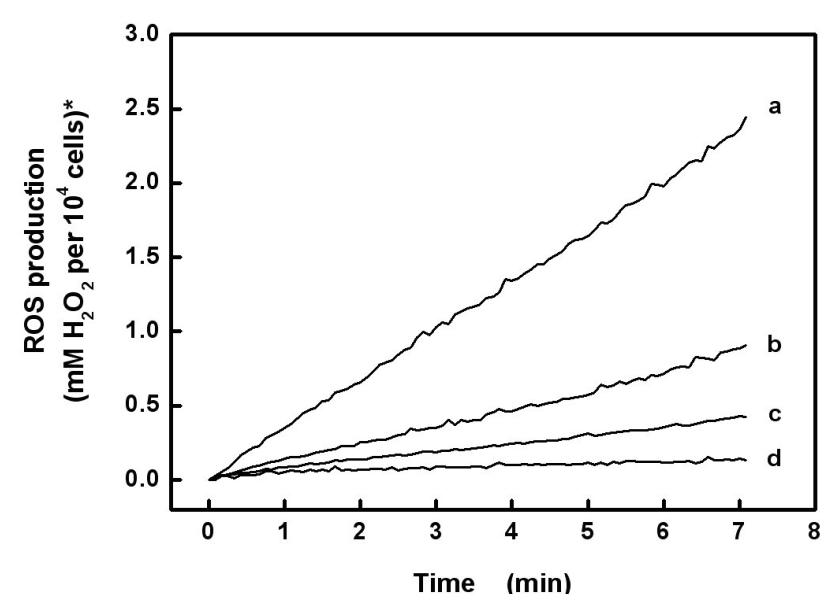

Fig. 2. ROS production traces reflect the dependence of $\mathrm{CM}$ $\mathrm{H}_{2}$ DCF oxidation rates in MCF7 cells on phthalocyanine sensitizer concentration during continuous irradiation with light intensity of $2 \times 10^{-3} \mathrm{~W} / \mathrm{cm}^{2}$. The representative traces were obtained from $\mathrm{CM}-\mathrm{H}_{2}$ DCFDA pretreated cells incubated with 100 (trace a), 10 (trace b), 1 (trace $\mathrm{c}$ ), and 0 (trace d) $\mu \mathrm{M}$ of $\mathrm{ClAlPCS}_{2}$ after ultrasound pretreatment. The ROS production was expressed in concentration units of $\mathrm{H}_{2} \mathrm{O}_{2}$ according to the procedure described in detail in the Methods.

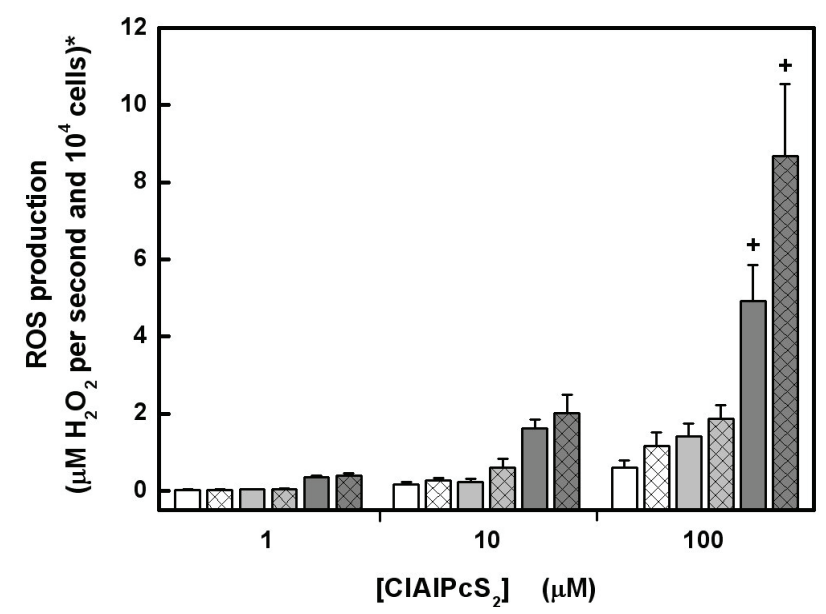

Fig. 3. Dependence of ROS production on concentration of CIAIPCS $_{2}$ during continuous irradiation with a light intensity of $5 \times$ $10^{-4} \mathrm{~W} / \mathrm{cm}^{2}$ (white bars), $1 \times 10^{-3} \mathrm{~W} / \mathrm{cm}^{2}$ (light gray bars), and $2 \times 10^{-3} \mathrm{~W} / \mathrm{cm}^{2}$ (dark gray bars) in ultrasound- nonpretreated (bars without pattern) and pretreated MCF7 cells (bars with crosshatch pattern). The rates of ROS production were calculated from the kinetic measurements for the first $4 \mathrm{~min}$ of irradiation. Their expression in concentration units of $\mathrm{H}_{2} \mathrm{O}_{2}$ is described in detail in the Methods section. Each value represents mean $\pm \mathrm{S}$.E. from 3 independent experiments. + ${ }^{+}$Significant difference compared to lower light intensity $(p<0.05)$.

MCF7 during PDT using $\mathrm{ClAlPcS}_{2}$ as a sensitizer. We did not investigate the direct effect of the ultrasound energy on the ROS production accompanying collapse of cavitation microbubbles, such as pyrolysis of water vapor. One reason is the higher intracellular viscosity, which creates worse conditions for the creation of acoustic cavitations (Honda et al. 2004). On the other

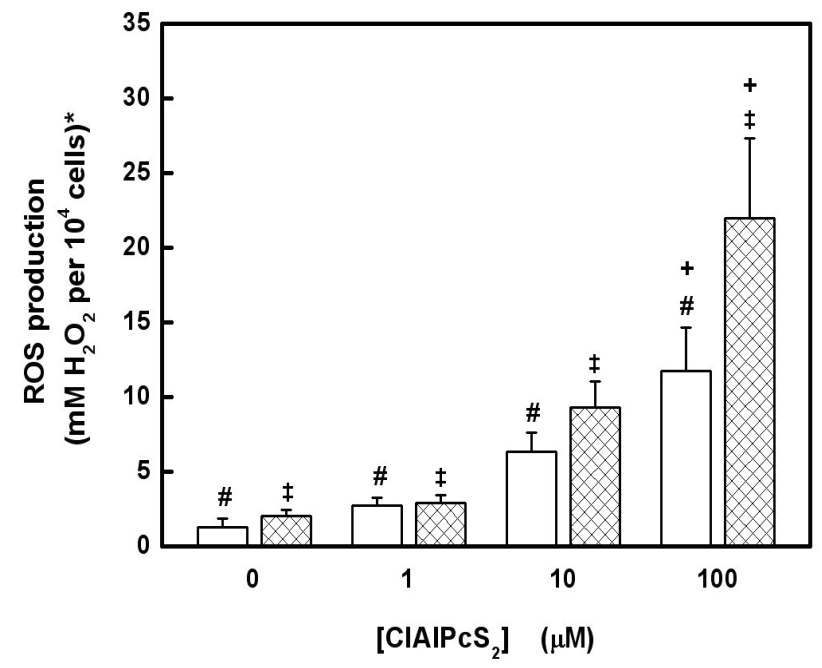

Fig. 4. Dependence of ROS production in MCF7 cells on concentration of $\mathrm{ClAIPcS}_{2}$ and ultrasound pretreatment (bars with crosshatch pattern) after irradiation with a light intensity of $20 \times$ $10^{-3} \mathrm{~W} / \mathrm{cm}^{2}$ for $8 \mathrm{~min}$ and $20 \mathrm{~s}$ resulting in a total dose of 10 $\mathrm{J} / \mathrm{cm}^{2}$. *The ROS production was expressed in concentration units of $\mathrm{H}_{2} \mathrm{O}_{2}$ according to the procedure described in detail in the Methods. Each value represents mean \pm S.E. from 3 independent experiments. 'Significant difference of the ultrasound pretreatment in the presence of the same sensitizer concentration $(p<0.05)$. ${ }^{\#, \neq}$ Significant differences compared to different sensitizer concentrations for ultrasound-nonpretreated and -pretreated cells, respectively ( $p<0.05$ ).

hand, when the microbubbles collapse, a part of the energy is transformed into light that can excite the photosensitizer. The phenomenon known as sonoluminescence has been investigated extensively. Under most conditions the intensity of sonoluminescence is very weak (Verall and Sehgal 1987). In addition, there is no evidence that the intensity is sufficient to excite phthalocyanine photosensitizers within cells. Our results showed a significant increase in ROS production, thus a significant effect of ultrasound pretreatment, for only MCF7 cells, which were incubated with the highest concentration of $\mathrm{ClAlPcS}_{2}(100 \mu \mathrm{M})$ and at a higher irradiation light intensity $\left(2 \times 10^{-3} \mathrm{~W} / \mathrm{cm}^{2}\right)$. Based on this fact, we suppose that there is a synergistic mechanism between SDT and PDT, which is involved in the ROS production within MCF7 cells and can be observed at the higher photodynamic conditions; sensitizer concentration and light intensity. It stands to reason that the total yield of ROS production affects the result of PDT. ROS overproduction causes severe cell damage and leads to cell death. In conclusion, we believe that the combination of SDT and PDT will bring medicine a new treatment modality for malignant and also nonmalignant diseases, although presently the mechanism of synergistic action is not fully explained. Miyoshi et al. (2001) showed that 
ultrasound induces monomerization of photosensitizers, which may increase the efficiency of PDT since only the monomers are photodynamically active. Moreover, when the photosensitizer accumulates in specific subcellular organelles, the ultrasound pretreatment can redistribute the photosensitizer to sites of higher vulnerability.

\section{Acknowledgements}

This work was supported by the Ministry of Education of the Czech Republic MSM 6198959216.

\section{Abbreviations}

$\mathrm{ClAlPcS}_{2}$, chloroaluminum phthalocyanine disulfonate; CM-H ${ }_{2}$ DCFDA, 5-(and-6)-chloromethyl-2', 7'dichlorodihydrofluorescein diacetate; DMEM, Dulbecco's modified Eagle's medium; LED, lightemitting diode; MCF7, human breast adenocarcinoma cell line; PBS, phosphate-buffered saline; PDT, photodynamic therapy; ROS, reactive oxygen species; SDT, sonodynamic therapy

\section{References}

HENDERSON BW, DOUGHERTY TJ: How does photodynamic therapy work? Photochem Photobiol 55: 145-157, 1992.

HIRAOKA W, HONDA H, FERIL LBJR, KUDO N, KONDO T: Comparison between sonodynamic effect and photodynamic effect with photosensitizers on free radical formation and cell killing. Ultrason Sonochem 13: 535-42, 2006.

HONDA H, KONDO T, ZHAO QL, FERIL LBJR, KITAGAWA H: Role of intracellular calcium ions and reactive oxygen species in apoptosis induced by ultrasound. Ultrasound Med Biol 30: 683-692, 2004.

JEFFERS RJ, FENG RQ, FOWLKES JB, HUNT JW, KESSEL D, CAIN CA: Dimethylformamide as an enhancer of cavitation-induced cell lysis in vitro. J Acoust Soc Am 97: 669-676, 1995.

KESSEL D, JEFFERS R, FOWLKES JB, CAIN C: Porphyrin-induced enhancement of ultrasound cytotoxicity. Int $J$ Radiat Biol 66: 221-228, 1994.

LARINA IV, EVERS BM, ESENALIEV RO: Optimal drug and gene delivery in cancer cells by ultrasound-induced cavitation. Anticancer Res 25: 149-156, 2005.

LEBEL CP, ISCHIROPOULOS H, BONDY SC: Evaluation of the probe 2',7'-dichlorofluorescin as an indicator of reactive oxygen species formation and oxidative stress. Chem Res Toxicol 5: 227-231, 1992.

MILOWSKA K, GABRYELAK T: Synergistic effect of ultrasound and phthalocyanines on nucleated erythrocytes in vitro. Ultrasound Med Biol 31: 1707-1712, 2005.

MISIK V, RIESZ P: Peroxyl radical formation in aqueous solutions of N,N-dimethylformamide, N-methylformamide, and dimethylsulfoxide by ultrasound: implications for sonosensitized cell killing. Free Radic Biol Med 20: 129-138, 1996.

MIYOSHI N, TAKESHITA T, MISIK V, RIESZ P: Monomerization of photosensitizers by ultrasound irradiation in surfactant micellar solutions. Ultrason Sonochem 8: 367-371, 2001.

NYMAN ES, HYNNINEN PH: Research advances in the use of tetrapyrrolic photosensitizers for photodynamic therapy. J Photochem Photobiol B 73: 1-28, 2004.

RIESZ P, KONDO T: Free radical formation induced by ultrasound and its biological implications. Free Radic Biol Med 13: 247-270, 1992.

SAKUSABE N, OKADA K, SATO K, KAMADA S, YOSHIDA Y, SUZUKI T: Enhanced sonodynamic antitumor effect of ultrasound in the presence of nonsteroidal anti-inflammatory drugs. Jpn J Cancer Res 90: 1146-1151, 1999.

SUSLICK KS: Sonochemistry. Science 247: 1439-1445, 1990.

TACHIBANA K, UCHIDA T, OGAWA K, YAMASHITA N, TAMURA K: Induction of cell-membrane porosity by ultrasound. Lancet 353: 1409, 1999.

UMEMURA K, YUMITA N, NISHIGAKI R, UMEMURA S: Sonodynamically induced antitumor effect of pheophorbide a. Cancer Lett 102: 151-157, 1996.

UMEMURA S, KAWABATA K, SASAKI K: In vitro and in vivo enhancement of sonodynamically active cavitation by second-harmonic superimposition. J Acoust Soc Am 101: 569-577, 1997. 
UMEMURA S, YUMITA N, NISHIGAKI R, UMEMURA K: Mechanism of cell damage by ultrasound in combination with hematoporphyrin. Jpn J Cancer Res 81: 962-966, 1990.

VERALL RE, SEHGAL CM: Sonoluminescence. Ultrasonics 25: 29-30, 1987.

WORTHINGTON AE, THOMPSON J, RAUTH AM, HUNT JW: Mechanism of ultrasound enhanced porphyrin cytotoxicity. Part I: A search for free radical effects. Ultrasound Med Biol 23: 1095-1105, 1997.

YUMITA N, NISHIGAKI R, UMEMURA K, UMEMURA S: Hematoporphyrin as a sensitizer of cell-damaging effect of ultrasound. Jpn J Cancer Res 80: 219-222, 1989.

ZAVODNIK IB, ZAVODNIK LB, BRYSZEWSKA MJ: The mechanism of Zn-phthalocyanine photosensitized lysis of human erythrocytes. J Photochem Photobiol B 67: 1-10, 2002.

\section{Corresponding author}

H. Kolářová, Department of Medical Biophysics, Faculty of Medicine, Palacký University, Hněvotínská 3, 77515

Olomouc, Czech Republic. E-mail: kol@tunw.upol.cz 